\title{
㴗
}

\section{DEMAND \\ ANALYSIS AND WILLINGNESS TO USE NEW MOBILITY CONCEPTS}

\author{
Kathrin Viergutz \\ German Aerospace Center (DLR e.V.), Institute of Transportation Systems \\ Florian Brinkmann \\ German Aerospace Center (DLR e.V.), Institute of Transportation Systems
}

\section{SUMMARY}

This conference contribution describes the results of an acceptance study of the properties of Demand-responsive Transport (DRT) by passengers and derives knowledge about the usability of these flexible mobility concepts as well as the willingness to share a ride. The aim is to determine the framework conditions under which DRTs could be used.

\section{DEMAND RESPONSIVE TRANSPORT (DRT)}

"It is important for me not to have long walks to the bus stop. I like busses that ride quickly and promptly and without interchanges. I also prefer routes without detours." That sounds like a typical statement of users of public transportation systems. In this conference contribution this presumption about the attitudes of passengers are kept under close scrutiny. The idea is that Demand-responsive Transport (DRT) is more suitable to meet the needs of passengers than line based transport systems.

Today's road users no longer rely on one means of transport, but often appreciate multimodality and prefer to use a wide range of complementary means of transport (Kuhnimhof, Buehler, Wirtz \& Kalinowska 2012). The socalled multimodal user combines the available transport options according to his current requirements. At the same time, there is a growing demand for flexibility and individualisation of transport from the perspective of travellers . Demand-responsive Transport systems are established especially in rural regions. But the demand of flexible mobility concepts particularly in the urban context increases more and more. Therefore, public transportation is currently experiencing a shift from the supply-oriented operation that is rigidly defined by schedules and route plans as well as fixed stops to a flexible, individually retrievable transport system, especially in the urban context. Such a flexible transport system is smoothly integrated into the everyday life of the users by means of its need-centered orientation, thus enabling the need-driven and spontaneously adaptable use of public transport. This described intelligent 
transportation system can be assigned as the highest level of service of bus on demand services defined by Proenca (2010).

The term Demand-responsive Transport describes responsive transport systems, which react dynamically to specific and spontaneous transport demands of passengers. Conventional public transportation systems have predominantly ex-ante constructed timetables. These target timetables indicate the time at which the stations that are located in the traffic network along defined routes are operated. In order to adapt the traffic offer to a variable demand, deviations from these defined stops, routes and operating times can be altered (Atasoy, Ikeda \& Ben-Akiva 2015). Various levels of flexibility in the supply are possible. The implementation of such alterations is often defined by legal conditions and operational regulation. Users of transport systems with a high level of flexibility can determine the start and destination points of their journey as well as the desired departure or arrival time within a certain operating area and within certain operating times as far as possible.

Some of the most important characteristics of DRT are:

- Flexible: No timetables, lines or fixed stops /stations

- Responsive: Demand-driven

- Door-to-door: Short access and egress distances

- Ad hoc: Low pre-booking period, high level of spontaneity

- Shared: Shared trips with other people

- Bundled: Routes with different source-target links are bundled

For passengers, the door-to-door features of a DRT result in a higher level of comfort in the sense of a mobility on demand. In this respect DRTs combine characteristics of conventional local transport and common taxi services (Mageean \& Nelson 2003). The difference is that there are other passengers with complementary destinations in the vehicle who have a similar route and get on and off during the journey. Currently there is a large number of global pilot projects in which such demand-driven systems are tested in an urban context. In doing so, these systems differ in parts in terms of their temporal and spatial flexibility, their degree of utilization, the spontaneity and the minimum time that is necessary to book a tour in advance, the operation of their access options and other characteristics.

The increasing demand for DRT reflects the need of users for a higher flexibility of rigidly operating transportation systems as well as mobility in 

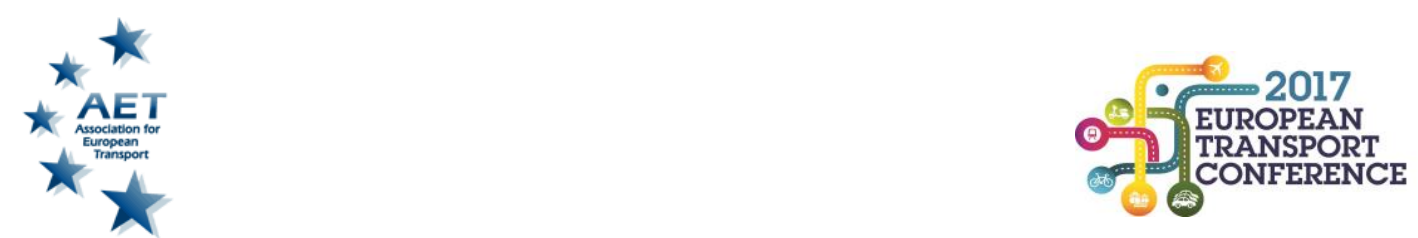

accordance with people's needs (Mulley \& Nelson 2009;). Demandresponsive Transport Systems assume a pre-booked ride request (Mulley \& Nelson 2009). Studies have shown that compared with conventional public transport systems the proportion of captive users of DRT is lower - that means that many passengers of DRT are choice riders who could have used the car but make a conscious decision for the DRT (Enoch, Potter, Parkhurst \& Smith 2004). The aim of this contribution is a closer monitoring of the needs of users of flexible public transportation systems.

\section{STUDY DESIGN AND APPROACH}

DRT are unfamiliar to most passengers. This is why it is difficult to assess their own willingness to use these flexible mobility concepts. For this reason, a passenger survey was carried out with the aim of exploring the acceptance of the properties of DRT - without informing the participants that the study is investigating DRT. The results of this study are presented in this paper.

Among other things, the question is asked whether the participants prefer direct connections instead of connections where they have to change. Another question concerns the importance of short walking distances to stations. In addition, the study deals with the acquisition of insights about the willingness to share a taxi with other persons - and under what conditions this would be the case. The evaluated study makes a valuable contribution to the research of passenger requirements for flexible mobility concepts.

\section{STUDY RESULTS}

\subsection{Study Participants}

Altogether 879 participants joined the survey that was open for about six weeks beginning from February 2017. The study was designed as an online questionnaire in German language. Almost two thirds of the participants are male and more than one third is female. The age distribution roughly is balanced: About 48 per cent of the participants are up to 40 years old.

A considerably big proportion of the participants is used to urban life: Almost half of them lives in cities with more than one million habitants. 62.3 percent own a transit pass for public transportation, i.e. a monthly pass, and 60.2 per cent hold a driver's licence. That is a significantly below-average ratio of licence ownership. In Germany the nationwide ratio stands at 86 per cent (Statistisches Bundesamt Deutschland 2016). From this result it might be 
reasonably assumed that the survey participants are familiar with the use of public transport systems and are aware about their needs.

\subsection{Key Findings: Waiting Periods and Interchange}

Key findings from literature research show that good conditions for comfortable interchanges are indispensable for the competitivenessof public transportation systems (Wardman \& Hine 2000). It in unsurprising that many studies reveal the reluctance of passengers to interchange (Paulley et al. 2006). Wardman, Hine \& Strading (2001) executed a meta study about penalty of interchange. The studies they cite in their paper differ about the time-effective or monetary amount of the penalty, but one perception can be found in every study: Interchange causes negative impact on the passenger's perceived quality of service. Additionally the studies found out that the intensity of the negative impact is influenced by the sex of the passenger, the carried luggage, the all-over travel time or the fact whether a person is timebound and needs to hurry.

Equally important are good conditions for waiting and short waiting periods. An evaluation of booking processes of the transportation network company Uberpool revealed that customers in general reject the transport offer when the waiting time is about 15 minutes (Myhrvold 2015). So that is the critical amount of time that decides whether a person will use a provided service or better will search for alternatives. Starting from a waiting time of about four minutes the likelihood of use is significantly reduced.

Short waiting periods are important for passengers. Even at high frequencies of service - i.e. headways of 5 minutes - passengers do not arrive randomly at the station but capture the right moment right before departure time (Luethi, Weidmann \& Nash 2006). This phenomenon can be observed especially during the morning peak when most commuters know the schedule. Consequently during the peak passengers are more timetable-dependent and have strong claims on punctuality and short waiting periods (Paulley et al. 2006).

Based on these perceptions of the literature research the presented study examined the willingness of passengers to wait on the station and to interchange during the ride. Unsurprisingly a big proportion (80.9 per cent) of the participants stated that they preferred direct connections to connections where they have to change. Still 61.0 per cent would prefer direct routes even 
if the overall travel time was 10 minutes higher than the travel time of the direct connections (which was presumed as 30 minutes).

Another question was concerned with the balance of the importance of short walks and direct connections. A scenario was given with two stations in the vicinity: One station is directly next to the position of the passenger but with only one bus line operating which requires to interchange to reach the destination. At the other station it is possible to ride directly to the destination, but the station is a 10 minutes' walk away. An amount of 66.7 per cent of the participants agreed that they would be willing to accept a walk of ten minutes to the station if then they would be able to ride continually. So the study revealed that in the given scenario passengers consider direct connections more important than short walking accesses. This was also confirmed when the participants were asked whether short walking distances would be that important for the participants that they would change a few times in order to minimize the walking distance. Only 22.1 per cent agreed, while 48.5 per cent of the participants disagreed and opted for avoiding the interchange (the rest of the answers was not specified).

Another question directly addressed the tolerability of waiting. The participants were asked what they would prefer in a scenario of a bus ride in the city of about half an hour: (1) A bus where they had to wait for a moment before driving off, but will arrive earlier at their destination - or (2) a bus line that starts instantly, bus will arrive later. As shown in Figure 1, a large majority of 68.9 per cent would opt for the faster ride even if it was necessary to wait for the departure. Only 29.6 per cent would prefer the bus that takes longer to the destination but allows them to get started instantly. This result indicated that waiting is tolerable on condition that the total travel time decreases consequently a fast ride is highly valued from passengers view. This result can be found across the entire range of age groups. 


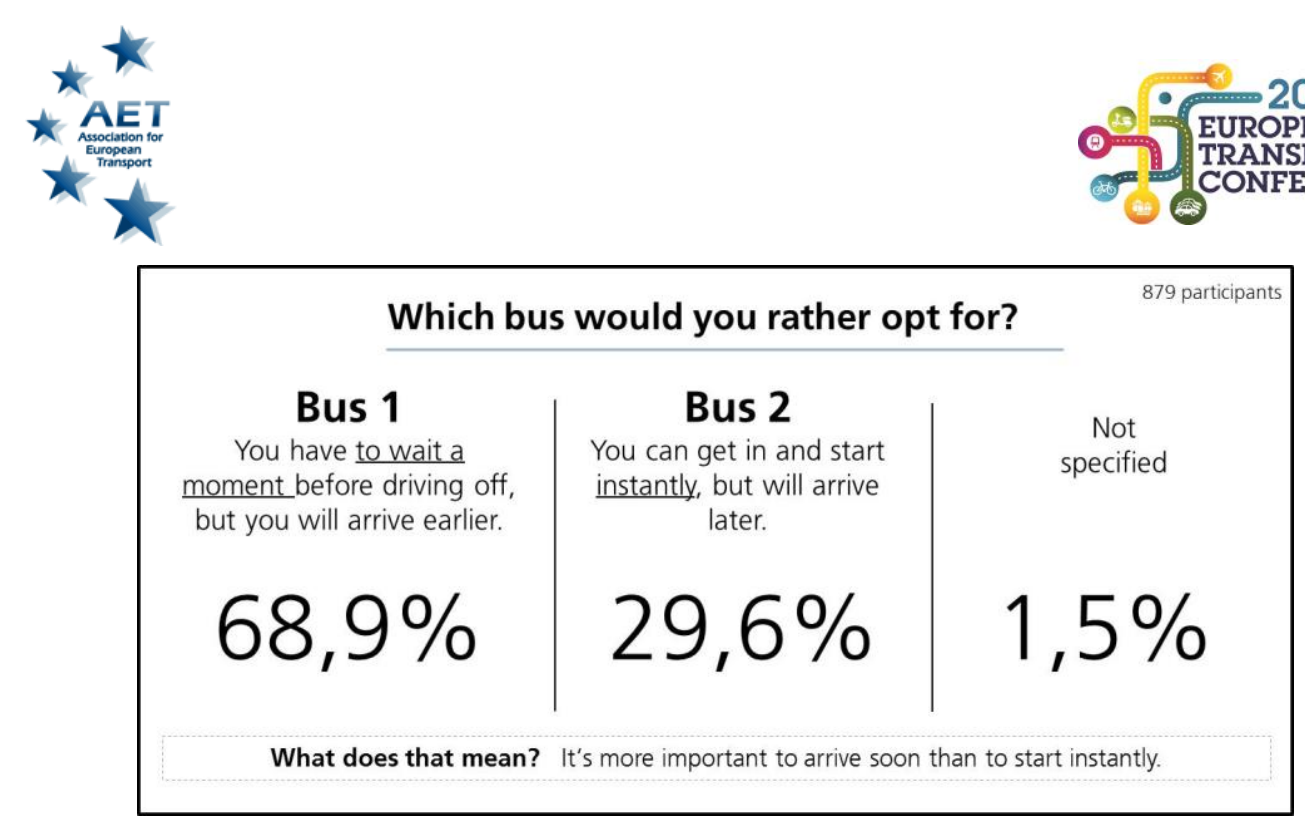

Figure 1: Waiting is tolerable on condition that the total travel time decreases.

Participants of every age group would prefer the faster ride (and would accept the accompanying waiting time), but the favor for the instant start increases with the age of the participants. While in the age group up to 20 years 83.7 per cent would opt for the faster ride, only 59.0 per cent of the age group over 60 years would prefer this ride.

\subsection{Key Findings: Accessibility of Stations and Walking Distances}

Good conditions for pedestrian access and egress of stations are key impacts to the willingness to use of public transportation (Beimborn, Greenwald \& Jin 2003). The closer a station is to the city center, the higher is the percentage of passengers who are walking from the egress station to their final destinations (Wiwobo \& Olszewski 2005). This figure relates to railway stations but it could serve as an indication for city transport as well. A study of Dill (2003) shows the correlation of the willingness to use and the walking distance to the rail station: The transit use reduces by 10 per cent with every 10 per cent increase in walking distance. A study among infrequent users revealed that an unsatisfactory access to underground stations is one of the most influential reasons why study participants are reluctant to use the underground (Wardman \& Hine 2000).

Taking these cited study results into consideration, one of the main subjects of the study which is presented in this paper is the passenger's acceptance of walking distances to stations. In this connection, the question arises as to how long the study participants are prepared to walk to a bus station. The answers to this open question - the amount of time that the participants were requested to specify in a provided text field - were classified afterwards. Figure 2 shows the surprising result: 44.5 per cent of the answers are between 8 and 10 minutes. That is a relatively high amount of time, considering the importance 
of short walking distances as seen in the previous literature review. This result is also reflected in the average of 9.3 walking minutes. There was the suspicion that younger participants would accept longer walks and the elderly preferred short distances. But during the analysis of the results no significant distinction between different age groups could be determined. Even the difference between the answers of big vs. small town dwellers is negligible. A reflection of the answers of transit pass owners and license owners returns only a small gap. This finding shows that walking to bus stations in generally acceptable.

How many minutes of walking to the bus stop would you be willing

Average: 9,3 minutes to accept?

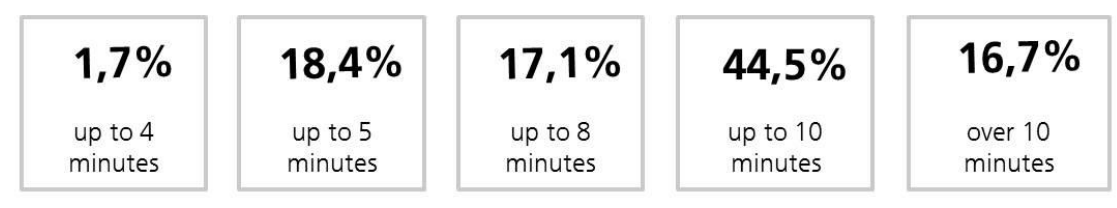

879 participants (classified text input)

What does that mean? Walking to bus stops is generally acceptable.

Figure 2: Walking to bus stops is generally acceptable.

The more stops along a bus line exist, the shorter are the access walks to the station. On the other hand, if there are fewer stops during the ride, busses do not need to stop frequently and can run faster. Therefore another question of the study concerned the participants' preference for few or many stops along a bus line. The task was to indicate the perfect amount of stops from the participants' point of view on a slider. The more left the participants adjusted the slider the fewer stops they would prefer - and the adjustment of the slider more to the right would imply that they would prefer a higher number of stops. The results were clustered into ten equidistant sections. The bar chart in Figure 3 shows that in general the participants adjusted the slider more on the left side than on the right side. That means that a majority would prefer fewer stops - and consequently a faster ride, even if it was accompanied by longer walks. 


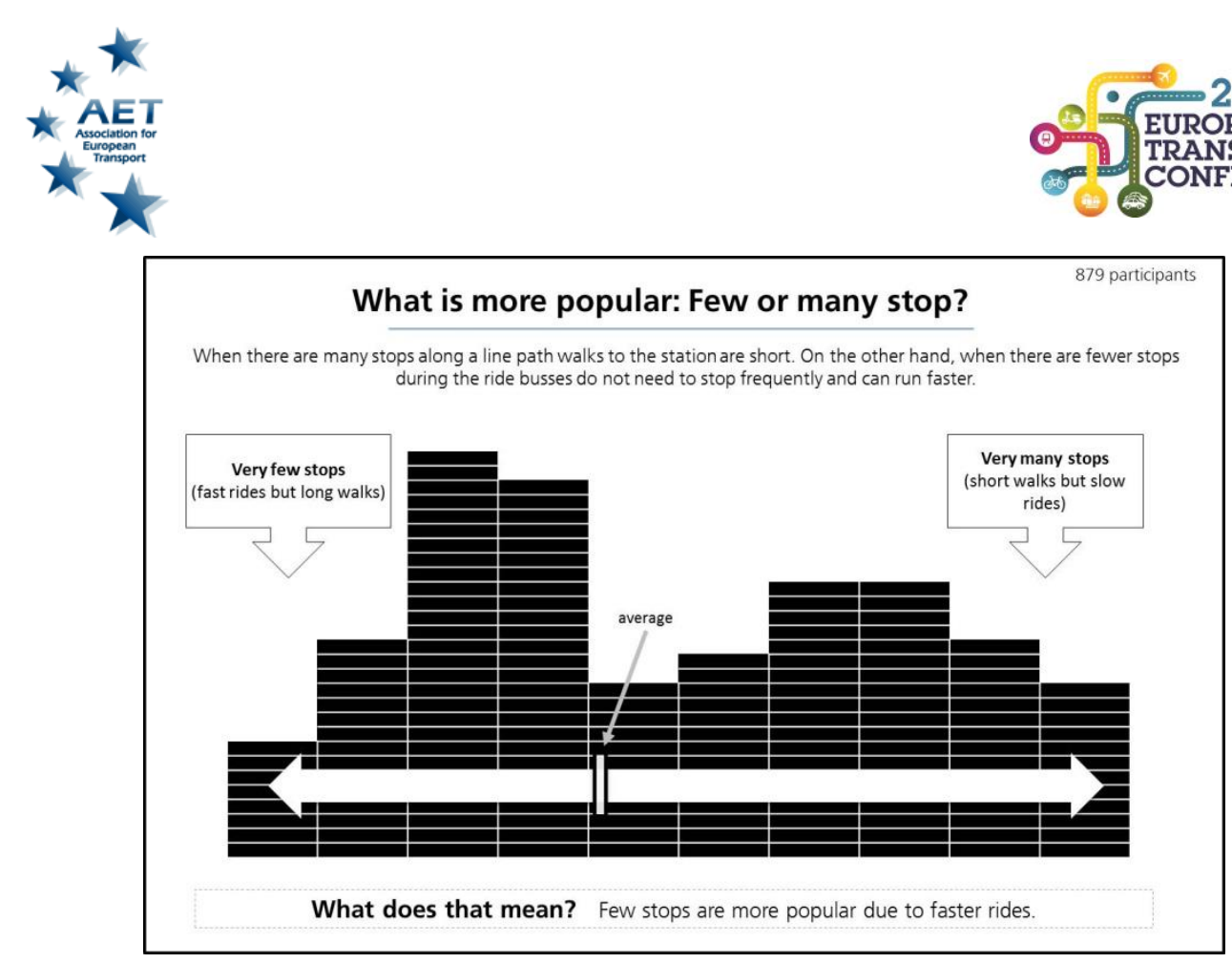

Figure 3: Few stops are more popular due to faster rides.

These results can be found in most age groups. The age groups "up to 20 years" until " 41 to 51 years" adjusted the slider in sum fairly equally slightly left of the "average" mark in the figure. Just the age groups "51 to 60 years" and "over 61 years" in sum put the slider slightly on the right side of the average but still roughly in the middle of the straight line. This observation reveals that for all age groups too many stops are undesired. Especially younger participants were found to accept longer walks in exchange for faster rides.

\subsection{Key Findings: Shared Mobility: Shared Taxis}

Digitalization opens the door to new possibilities for matching. For transportation management this means that it is possible to match different incoming ride requests to create an interrelated route through a considered service area by means of a matching algorithm. This use of information and communication technology distinguishes ridesharing from traditional taxicab operators (Rayle et al. 2016). That is how transportation network companies (TNCs) like Uberpool, Sidecar or Lyft Line work. Another conceivable applicability of this matching capability is the merging of requests of passengers of conventional taxi services. Some approaches can be found where taxi passengers' requests are bundled. As one example Bandwagon Inc. can be named. Bandwagon is a concept that allows taxi passengers to connect with other taxi passengers with similar routes starting from selected points in New York, e.g. at the airports JFK and LaGuardia, for a common taxi ride to their destination and a shared fare (Bandwagon Inc. 2017). TNCs are 

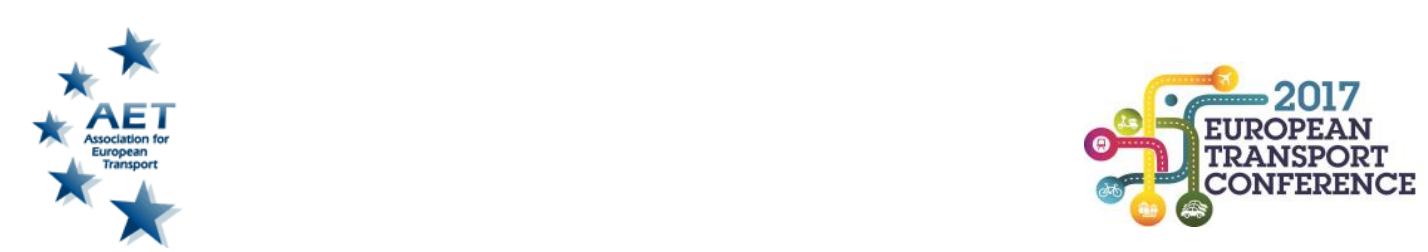

experiencing an upswing during the past few years. In San Francisco in autumn 2014 there have been more than twice as many TNC-rides than single taxi rides (San Francisco Municipal Transportation Agency 2015).

An analysis of Rayle et al. (2016) illustrates that sharing rides with other people carries the advantage for passengers that fares are lower and rides potentially can be less stressful. Furthermore, in long-range view, travel times can be sustainably reduced due to less intense traffic. On the other hand passengers could experience the disadvantage that shared rides give less privacy than a single ride. Besides passengers could perceive a shared ride as less flexible and less convenient or could feel that their need for security might not be fulfilled sufficiently.

In the light of these insights, some questions that enquire the willingness to share a taxi were included in the questionnaire. More precisely the intention was to find out under which circumstances taxi passengers would share a taxi with other people they do not know. The participants were asked how to decide in a scenario of a basic taxi ride of 30 minutes if (1) the route was exactly the same vs. a small detour of about 10 minutes was necessary and (2) the fare was the same vs. a reduced fare? The results show that the study participants would be willing to share a taxi with other foreign people if this means that the fare was reduced. In this case even a small detour was accepted. This result once again shows that passengers are price sensitive and that fares are a major criterion. The high impact of costs on the mode choice is a result that can be found in many studies, for example in the metastudy of Collins \& Chambers (2005).

\section{KEY FINDINGS OF THE PRESENTED STUDY}

- Direct connections are important for passengers. For this, a somewhat longer journey or walking distances are accepted.

- In all age classes walking to bus stops is generally acceptable.

- Speediness is important. For younger passengers the rapid arrival is even more important than for older ones.

- It is more important to arrive soon than to start instantly. Waiting is tolerable on condition that the total travel time decreases.

- Few stops (and thereby a faster ride) are more popular than many stops. Especially younger passengers prefer few stops.

- When the fare is lower, participants are willing to share a taxi. Even a short detour is accepted. 


\section{袪}

\section{CONCLUSION AND OUTLOOK}

The presented study shows that fast and convenient rides with a small number of interchanges are important from the passengers' perspective. In exchange even longer walking distances are accepted. The study proves the presumption that future public transportation systems should be capable to provide a flexible and customizable mobility for users. Further research activities should focus on the relation and the interdependence of the considered characteristic values. The demands of passengers could be analyzed for instance within a conjoint analysis.

\section{BIBLIOGRAPHY}

Atasoy, B.; Ikeda, T., Song, X.; Ben-Akiva, M. (2015), "The Concept and Impact Analysis of a Flexible Mobility on Demand System", Transportation Research Part C: Emerging Technologies, Vol. 56, pp. 373-392 Bandwagon Inc. (2017) Smarter, faster, better transit. Shrinking taxi lines at airports, events, in cities and beyond. Website: www.bandwagon.io

Beimborn, E.; Gerenwald, M.; Jin, X. (2003) Accessibility, Connectivity and Captivity: Impacts on Transit Choice. Transportation Research Record Journal of the Transportation Research Board 1835(1835)

Collins, C.; Chambers, S. (2005) Psychological and Situational Influences on Commuter-Transport-Choice. Environment and Behavior, Vol. 37 No. 5, 2005.

Dill, J. (2003) Transit use and proximity to rail: results from large employment sites in the San Francisco, California, bay area. Transportation Research Record No. 1835, p. 19-24.

Enoch, M.; Potter, S.; Parkhurst, G.; Smith, M. (2004) Intermode: Innovations in Demand Responsive Transport. Department for Transport and Greater Manchester Passenger Transport Executive, June 2004, Final Report.

Kuhnimhof, T.; Buehler, R.; Wirtz, M.; Kalinowska, D. (2012): Travel trends among young adults in Germany: increasing multimodality and declining car use for men. Journal of Transport Geography 24 (2012), p. 443-450.

Luethi, M.; Weidmann, U.; Nash, A. (2006): Passenger arrival rates at public transportation stations. In: 86th Transportation Research Board Annual Meeting. 2007Mageean, J. and Nelson, J.D., (2003) The evaluation of 

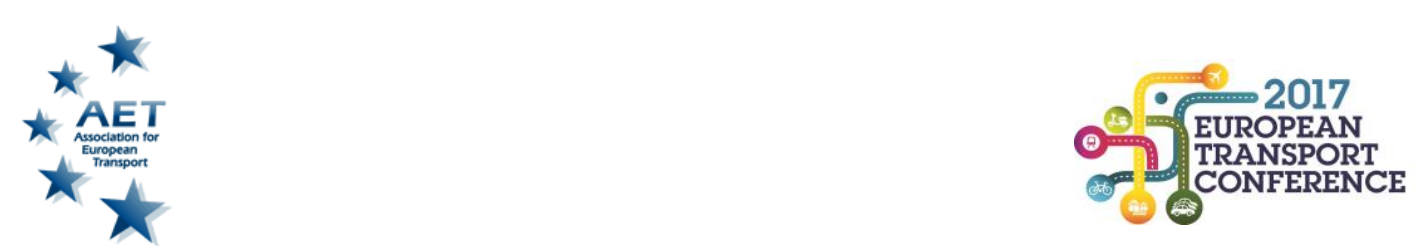

Demand Responsive Transport Services in Europe. Journal of Transport geography. 11 (2003), p. 255 - 270. Elsevier, UK.

Mulley, C.; Nelson, J. (2009) Flexible transport services: A new market opportunity for public transport. Research in Transportation Economics, 25. Aufl., p. 39-45.

Myhrvold, C. (2015) Uber Expectations As We Grow. Available at: https://newsroom.uber.com/uber-expectations-as-we-grow/

Paulley, N.; Balcombe, R.; Mackett, R.; Titheridge, H.; Preston, J.; Wardman, M.; Shires, J.; White, P. (2006): The demand for public transport: The effects of fares, quality of service, income and car ownership. Transport Policy 13(4):295-306.

Proença, F. (2010) Bus on Demand. Doctoral Thesis, Instituto Superior Técnico, Taguspark, October 2010 Available at: https://fenix.tecnico.ulisboa.pt/downloadFile/395142077593/ resumo.pdf

Rayle, L.; Dai, D.; Chan, N.; Cervero, R.; Shaheen, S. (2016) Just a better taxi? A survey-based comparison of taxis, transit, and ridesourcing services in San Fransisco. Transport Policy 45 (2016), p.168-178.

San Francisco Municipal Transportation Agency (2015): Travel Decisions Survey 2014. Summary Report. Available at: https://www.sfmta.com/sites /default/files/reports/2015/Travel\%20Decision\%20Survey\%202014\%20Summ ary\%20Report.pdf

Statistisches Bundesamt Deutschland (2016) Räumliche Mobilität und regionale Unterschiede, Auszug aus dem Datenreport 2016, vol. 11.

Wardman, M.; Hine, J. (2000): Costs of Interchange: A Review of the Literature. Institute of Transport Studies, University of Leeds, Working Paper 546.Wardman, M.; Hine, J.; Strading, S. (2001) Interchange and Travel Choice Volume 2. Report for the Scottish Executive by the Institute for Transport Studies at the University of Leeds and the Transport Research Institute at Napier University. Scottish Executive Central Research Unit 2001.

Wiwobo, S. S.; Olszewski, P. (2005) Modeling Accessibility to Public Transport Terminals: Case Study of Singapore. Journal of the Eastern Asia Society for Transportation Studies, Vol. 6, pp. 147 - 156, 2005. 